\title{
Studies of concentration dependences in the luminescence of Ti-doped $\mathrm{Al}_{2} \mathrm{O}_{3}$
}

\author{
V. B. Mikhailik, ${ }^{1,2, a)}$ P. C. F. Di Stefano,,${ }^{3,4}$ S. Henry, ${ }^{1}$ H. Kraus, ${ }^{1}$ A. Lynch, ${ }^{1}$ V. Tsybulskyi, ${ }^{5}$ \\ and M. A. Verdier ${ }^{3}$ \\ ${ }^{1}$ Department of Physics, University of Oxford, Keble Road, Oxford OXI 3RH, United Kingdom \\ ${ }^{2}$ Diamond Light Source, Harwell Science Campus, Didcot OX11 ODE, United Kingdom \\ ${ }^{3}$ Université de Lyon, Université Lyon 1, CNRS/IN2P3, UMR5822, Institut de Physique Nucléaire de Lyon, \\ F-69622 Villeurbanne, France \\ ${ }^{4}$ Department of Physics, Queen's University, Kingston K7L 3N6, Canada \\ ${ }^{5}$ Physics Department, Lviv National University, 8 Kyryla and Mefodiya Str., Lviv 79005, Ukraine
}

(Received 30 September 2010; accepted 5 January 2011; published online 15 March 2011)

\begin{abstract}
The variation of luminescence and excitation spectra of titanium doped $\mathrm{Al}_{2} \mathrm{O}_{3}$ for the concentration of Ti ranging from 10 to $1000 \mathrm{ppm}$ was investigated using synchrotron radiation. In the lightly doped $\mathrm{Al}_{2} \mathrm{O}_{3}-\mathrm{Ti}(<100 \mathrm{ppm})$ samples we identified several emission bands. These are the emission of the excitons localized at $\mathrm{Ti}(290 \mathrm{~nm})$, the emission due to $\mathrm{F}^{+}$centers $(325 \mathrm{~nm})$, the band around $420 \mathrm{~nm}$ traditionally attributed to $\mathrm{F}$ center emission, and the luminescence of $\mathrm{Ti}^{3+}$ ions at $720 \mathrm{~nm}$. The emphasis in this study is on the clarification of the nature of the blue emission band in the samples with high concentration of $\mathrm{Ti}(\geq 100 \mathrm{ppm})$, where the luminescence and excitation spectra of the blue emission exhibit noticeable variability. This is explained by a model of the luminescence process of $\mathrm{Ti}^{4+}-\mathrm{F}$ centers that includes the photoionization of $\mathrm{Ti}^{3+}$, the subsequent capture of electrons at $\mathrm{F}^{+}-$ centers, formation of excited F-centers and, finally, the emission of a blue photon. The quenching of the blue emission with increasing Ti concentration is interpreted in terms of competition between oxygen vacancies and $\mathrm{Ti}^{4+}$ centers in the capture of the electron. (C) 2011 American Institute of Physics. [doi:10.1063/1.3552943]
\end{abstract}

\section{INTRODUCTION}

A prominent feature of $\mathrm{Al}_{2} \mathrm{O}_{3}$ sapphire crystals is the ubiquitous emission spread over a broad spectral range from ultraviolet to near infrared. This emission has received significant attention over decades in view of applications of $\mathrm{Al}_{2} \mathrm{O}_{3}$ that rely upon the luminescence performance of the material. The most renowned examples of such applications are $\mathrm{Cr}$ - and Ti-doped sapphire lasers that underpinned the development of modern laser technologies. Radiation dosimetry and scintillation detection are two other areas where the use of luminescent $\mathrm{Al}_{2} \mathrm{O}_{3}$ facilitated significant improvement and created new opportunities for radiation monitoring.

Because of such practical importance, there have been a large number of comprehensive studies of pure and doped sapphire (see, e.g., Refs. 1-6) that form the basis of our present knowledge of the emission properties of $\mathrm{Al}_{2} \mathrm{O}_{3}$. However none of these studies are entirely systematic in their choice of experimental samples. In all cases, the samples used in the experiments studies were either obtained from different suppliers, or they were produced by different methods, or subjected to different thermochemical treatments. Whatever the justification for any particular choice of samples was, this created an inevitable ambiguity in the interpretation of some findings; and the possibilities for comparing results from different studies are limited further due to different experimen-

\footnotetext{
a) Author to whom correspondence should be addressed. Electronic mail: vmikhai@hotmail.com. Fax: 44-01865-273418.
}

tal techniques used. A prominent example is an ambiguity in the assignment of the blue emission of sapphire.

There have been two major hypotheses on the origin of this emission. Since the blue emission of $\mathrm{Ti}^{4+}$ ions is a characteristic emission of wide-gap hosts ${ }^{7,8}$ stimulated through charge-transfer transitions, the corresponding assignment of

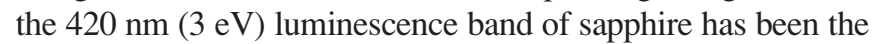
subject of many publications since the end of the last century. ${ }^{1,3,9-14}$ Another hypothesis attributes this band to the emission of $\mathrm{F}^{+}$or $\mathrm{F}$ defect centers (an oxygen vacancy occupied by one or two electrons, respectively) ever-present in aluminum oxide. ${ }^{15-17}$ The existing ambiguity in the assignment of this luminescence has been acknowledged ${ }^{2,18}$ and it has been suggested that there are several clear features permitting to discriminate between the impurity and defect emission, such as band half-width, excitation spectra, lifetimes etc. Nonetheless, it seems that various studies of the blue emission of sapphire report properties that are consistent with either one or the other hypothesis. As the luminescence of $\mathrm{Al}_{2} \mathrm{O}_{3}$ can be significantly modified by impurities and thermochemical treatment it is reasonable to assume that the blue emission could be due to more than one cause. Proving this would be the major step toward reconciliation of the existing discrepancy.

Recently we have initiated studies of Ti doped $\mathrm{Al}_{2} \mathrm{O}_{3}$ in view of possible application of this material as a scintillation target in cryogenic experiments searching for rare events. ${ }^{19}$ The optimization of the scintillation properties of materials for this application requires a detailed understanding of the emission process at high-energy excitation and over a wide 
temperature range. This prompted a systematic investigation of the emission properties of sapphire as a function of temperature, excitation conditions and $\mathrm{Ti}$ concentration. ${ }^{18,20-22} \mathrm{It}$ has been shown that these studies on the concentration dependence can help explain the origin of the ubiquitous emission of $\mathrm{Al}_{2} \mathrm{O}_{3}$. This motivated further systematic investigations of the emission and excitation spectra of aluminum oxide with different concentration of $\mathrm{Ti}$ as well as anion-deficient $\mathrm{Al}_{2} \mathrm{O}_{3}$ using vacuum ultraviolet (VUV) synchrotron radiation.

\section{EXPERIMENTS}

The samples of $\mathrm{Al}_{2} \mathrm{O}_{3}$ crystals doped with Ti were produced at the Institute for Single Crystals (Kharkiv, Ukraine) by the Czochralski method. The crystals have been annealed in strongly reducing conditions (redox potential $-230 \mathrm{~kJ} / \mathrm{mol}$ ) that favors conversion of Ti into its $3+$ valence state. ${ }^{6}$ It is important to stress that the samples have been produced in the same conditions, providing the necessary benchmark for the comparison and interpretation of the results. The nominal concentrations of $\mathrm{Ti}$ in the samples, specified by the manufacturer, were 10, 50, 100, 500, and $1000 \mathrm{ppm}$.

The sample of anion-deficient $\mathrm{Al}_{2} \mathrm{O}_{3}$ from the same manufacturer was produced by annealing in a strongly reducing atmosphere that is required for the formation of $\mathrm{F}^{+}$or $\mathrm{F}$ defect centers. It was supplied as nominally pure, though present studies revealed that it contains inadvertent impurities of $\mathrm{Cr}^{3+}$ and $\mathrm{Ti}^{3+}$ (see below).

The studies of the luminescence properties have been carried out at the SUPERLUMI station of HASYLAB, which is designed for comprehensive investigations of luminescence materials in the VUV range. ${ }^{23}$ The $5 \times 5 \times 1 \mathrm{~mm}^{3}$ samples (cut perpendicular to optical axis c) were polished to optical quality and glued to the sample holder of a Heflow cryostat. Different samples were presented to the excitation radiation by translating the holder in a direction orthogonal to the beam. The fixed geometry of the experiment as well as the equal size and the surface finish of the samples allow a direct comparison of the intensity of the light emitted by the crystals.

For the measurements of excitation spectra, the emission band was selected by a SpectraPro308 (Action Research) monochromator and recorded with a Hamamatsu, R6358P Photomultiplier tube (PMT). The excitation spectra were normalized to equal quantum intensity of the synchrotron radiation by dividing for the response of a sample of sodium salicylate that has constant quantum yield over the energy range of interest.

The emission spectra were measured at fixed excitation wavelength using a liquid nitrogen cooled CCD camera (Princeton Instruments), mounted on the second exit arm of the monochromator. To eliminate the second order effect of the grating monochromator, a GG420 cut-off filter was placed in front of the entrance slit for the measurements in the 450-900 nm spectral range. The measurements of the optical absorption spectra were made using a Perkin-Elmer Lambda 9 absorption spectrometer.

\section{RESULTS AND DISCUSSION}

Three emission bands have been previously detected in the luminescence spectra of Ti-doped $\mathrm{Al}_{2} \mathrm{O}_{3}$ at high energy excitation (x-ray or VUV), i.e., 290, 425, and near IR bands around $750 \mathrm{~nm} .^{18,20,21}$ The emission spectra of the studied samples measured at $\mathrm{T}=300$ and $8 \mathrm{~K}$ are shown in Fig. 1. The investigation of concentration dependence at selected excitation revealed additional features of the luminescence spectra of $\mathrm{Al}_{2} \mathrm{O}_{3}-\mathrm{Ti}$ that have not been previously reported. There is a noticeable difference in the luminescence of samples with low $(<100 \mathrm{ppm})$ and high $(\geq 100 \mathrm{ppm})$ concentration of Ti. At excitation with high energy photons $(7.1 \mathrm{eV})$ the emission spectra of $\mathrm{Al}_{2} \mathrm{O}_{3}-\mathrm{Ti}$ with high concentration exhibits two bands at about 300 and $730 \mathrm{~nm}$. Note that the mismatch in the observed position of the near IR band (730 $\mathrm{nm}$ against generally quoted value of $750 \mathrm{~nm}$ ) is due to the difficulties of the correction for the instrumental response of the detection system in this spectral range. The origin of the
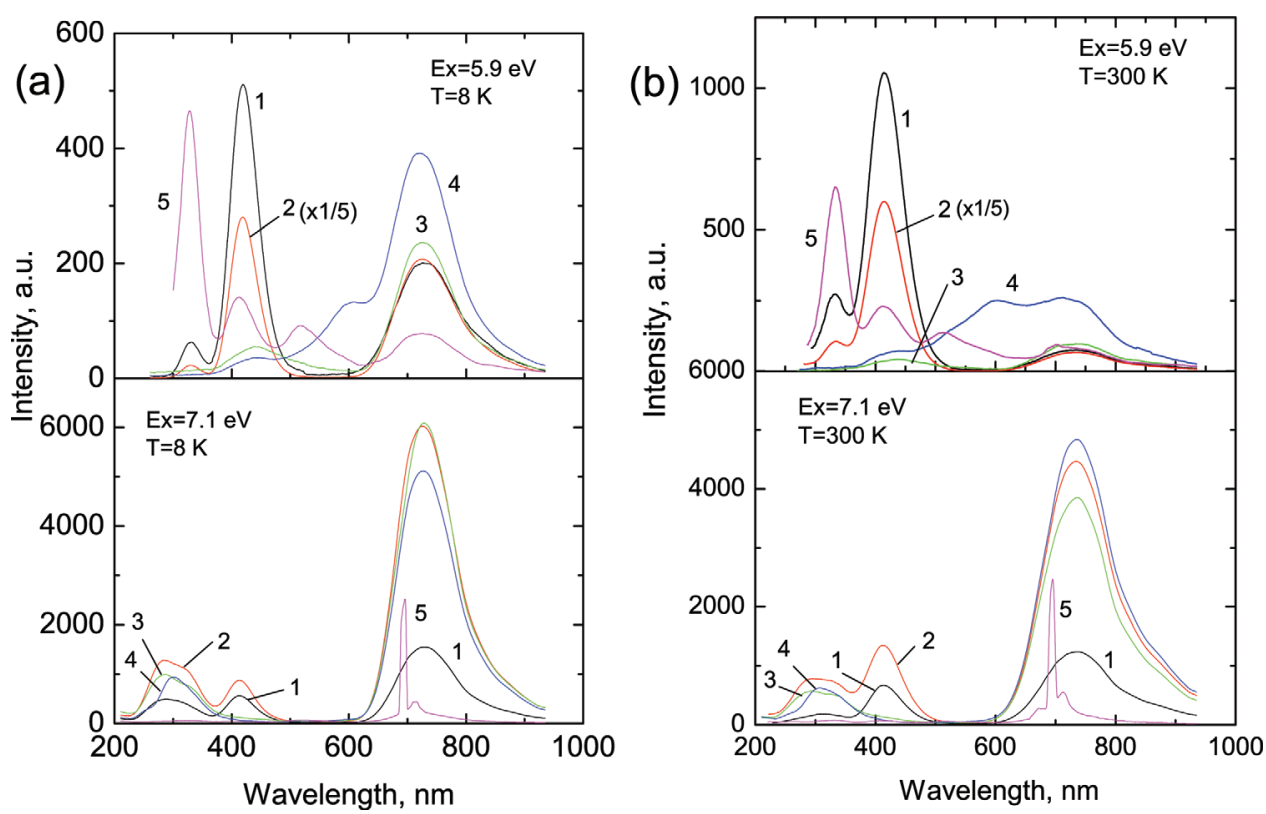

FIG. 1. (Color online) Luminescence spectra of $\mathrm{Al}_{2} \mathrm{O}_{3}$ doped with 10 (1), 50 (2), 100 (3), and $500 \mathrm{ppm}$ of Ti (4) and anion-deficient $\mathrm{Al}_{2} \mathrm{O}_{3}$ (5). Spectra are monitored at excitation with 5.9 and 7.1 $\mathrm{eV}$ photons. $\mathrm{T}=8$ (left) and $300 \mathrm{~K}$ (right). 


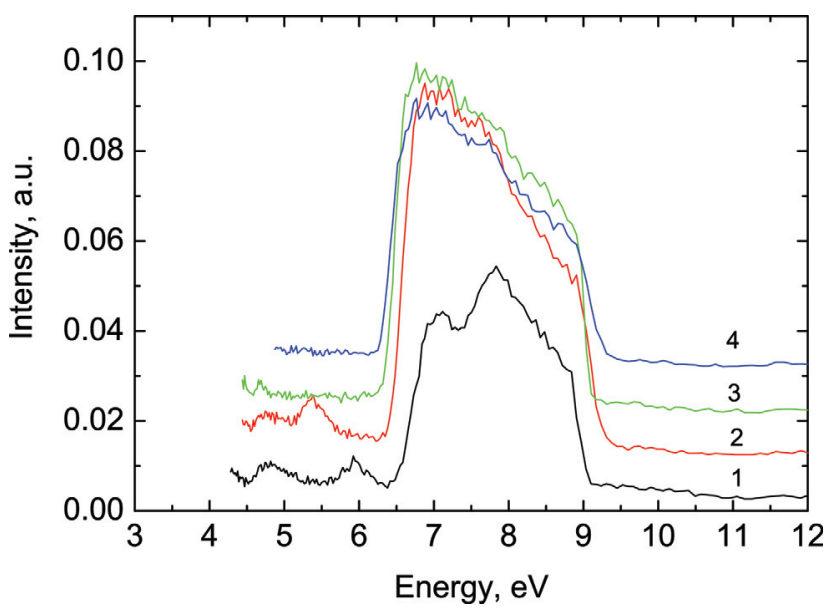

FIG. 2. (Color online) Excitation spectra monitored at $290 \mathrm{~nm}$ in $\mathrm{Al}_{2} \mathrm{O}_{3}$ doped with 10 (1), 50 (2), 100 (3), and 500 ppm of Ti (4). T=8 K. Spectra are vertically shifted.

near IR emission band has been long agreed as being due to the ${ }^{2} \mathrm{E} \rightarrow{ }^{2} \mathrm{~T}_{2}$ radiative transition of $\mathrm{Ti}^{3+}$ ions. The luminescence spectra of the samples with low $\mathrm{Ti}$ concentration clearly show that the emission in ultraviolet region is composed of two bands peaking at 290 and $325 \mathrm{~nm}$. Recent studies of the $290 \mathrm{~nm}$ band have assigned this emission to the radiative decay of excitons localized at activator ions. ${ }^{18,20}$ The prominent feature of the emission spectra at excitation with $7.1 \mathrm{eV}$ photons is the characteristic blue band at $420 \mathrm{~nm}$ in lightly doped $\mathrm{Al}_{2} \mathrm{O}_{3}-\mathrm{Ti}$, which is absent in the samples with Ti concentration $\geq 100 \mathrm{ppm}$.

At the excitation with $5.9 \mathrm{eV}$ photons the 325 and 420 $\mathrm{nm}$ bands observed in lightly doped $\mathrm{Al}_{2} \mathrm{O}_{3}-\mathrm{Ti}$ are more distinctive; they also exhibit a conspicuous decrease with cooling. The comparison of these emissions with the luminescence spectra of anion-deficient $\mathrm{Al}_{2} \mathrm{O}_{3}$ suggests straightforward assignment for the $325 \mathrm{~nm}$ and $420 \mathrm{~nm}$ bands. It is well established that excitation at $5.9 \mathrm{eV}$ results in the emission of $\mathrm{F}^{+}$and $\mathrm{F}$ centers in $\mathrm{Al}_{2} \mathrm{O}_{3}$, peaked at 325 and $420 \mathrm{~nm}$ respectively. ${ }^{2,24,25}$ The similarity of these two bands with the emission observed in the samples with low Ti concentration, supports the notion that they are of the same origin in undoped and doped samples of $\mathrm{Al}_{2} \mathrm{O}_{3}$. Further evidence is obtained from the analysis of the excitation spectra and kinetic characteristics of emission bands.

When the concentration of titanium in the sample reaches ca. $100 \mathrm{ppm}$ the $325 \mathrm{~nm}$ band vanishes, while the appearance of the blue emission changes: the maximum shifts to $425 \mathrm{~nm}$, and becomes noticeably broader and less sensitive to the change of temperature. This indicates a change in the emission mechanism that is further supported by analysis of the excitation spectra. The intensity of the $425 \mathrm{~nm}$ band in $\mathrm{Al}_{2} \mathrm{O}_{3}$ with $100 \mathrm{ppm} \mathrm{Ti}$ is comparable with that of the $730 \mathrm{~nm}$ band at excitation with $5.9 \mathrm{eV}(\mathrm{T}=300 \mathrm{~K})$. In the sample with even higher Ti concentration (500 ppm) the blue emission of $\mathrm{Al}_{2} \mathrm{O}_{3}$ decreases, whereas a new luminescence band emerges at $600 \mathrm{~nm}$. The intensity of this band increases with the concentration of titanium, so that in the sample with the $1000 \mathrm{ppm}$ it dominates the luminescence at room temperature and low energy excitation $(5.9 \mathrm{eV})$.
The anion-deficient $\mathrm{Al}_{2} \mathrm{O}_{3}$ sample exhibits a narrow line at $693 \mathrm{~nm}$ at excitation with $7.1 \mathrm{eV}$ photons that is a distinctive feature of $\mathrm{Cr}^{3+}$ emission $\left({ }^{2} \mathrm{E} \rightarrow{ }^{4} \mathrm{~A}_{2}\right.$ transitions). Excitation with $5.9 \mathrm{eV}$ photons results in a broad emission band at $730 \mathrm{~nm}$. This indicates that the sample contains impurities of chromium and titanium. The presence of these impurities in nominally pure samples is a fairly common feature for $\mathrm{Al}_{2} \mathrm{O}_{3}{ }^{2,26-28}$ The luminescence band at $510 \mathrm{~nm}$ observed in anion-deficient $\mathrm{Al}_{2} \mathrm{O}_{3}$ has been attributed to donor centers like interstitial aluminum ions ${ }^{29}$ and this assignment prevailed for long. ${ }^{5,27}$ However the authors of Ref. 29 also mentioned that $\mathrm{F}_{2}$ centers can yield emission in this region and latest studies provided comprehensive support for such divacancy model of the emission center. ${ }^{25,30}$

The next step is to establish the changes in the excitation spectra with the titanium concentration. Figure 2 shows that the excitation spectra of the $290 \mathrm{~nm}$ band in $\mathrm{Al}_{2} \mathrm{O}_{3}-\mathrm{Ti}$ are very similar for all concentrations. The broad band of asymmetrical shape exhibits a steep onset at $6.2 \mathrm{eV}$ and vanishes above $9 \mathrm{eV}$. This reproduces well the excitation spectrum of ultraviolet emission in $\mathrm{Al}_{2} \mathrm{O}_{3}-\mathrm{Ti}$ reported earlier. ${ }^{18,20}$

The excitation spectra of the $325 \mathrm{~nm}$ band measured in Ti-doped and anion-deficient crystals of $\mathrm{Al}_{2} \mathrm{O}_{3}$ are displayed in Fig. 3. The low energy part of the spectra is fitted by Gaussians revealing three individual bands with their maxima at 4.85, 5.37, and $5.92 \mathrm{eV}$, which is an unmistakable signature of $\mathrm{F}^{+}$centers. ${ }^{26,31-33}$ The excitation spectrum of the Ti-doped sample exhibits an additional broad band between 6.5 and $9 \mathrm{eV}$ that is very similar to the excitation spectrum of the $290 \mathrm{~nm}$ band. The appearance of this additional band in the excitation spectrum under discussion can be readily explained by spectral overlap of the 290 and $325 \mathrm{~nm}$ emission bands. It is also found that these overlapping emission bands in the Ti-doped samples exhibit distinctively different kinetics characteristics. The decay time constants of the 290 and $325 \mathrm{~nm}$ emission bands at $300 \mathrm{~K}$ are 140 and $2 \mathrm{~ns}$, respectively. The first value agrees very well with the decay time constant measured by us earlier for the $290 \mathrm{~nm}$ band in

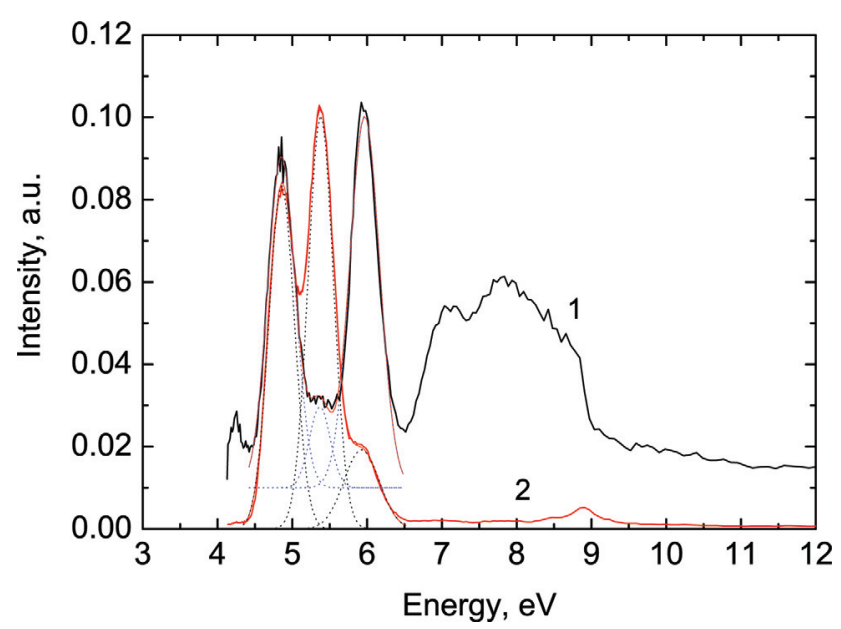

FIG. 3. (Color online) Excitation spectra monitored at $325 \mathrm{~nm}$ in $\mathrm{Al}_{2} \mathrm{O}_{3}$ doped with $10 \mathrm{ppm}$ of $\mathrm{Ti}$ (1) and anion-deficient $\mathrm{Al}_{2} \mathrm{O}_{3}$ (2). $\mathrm{T}=8 \mathrm{~K}$. The low energy part of the spectra is fitted by three Gaussians. Spectra are vertically shifted. 


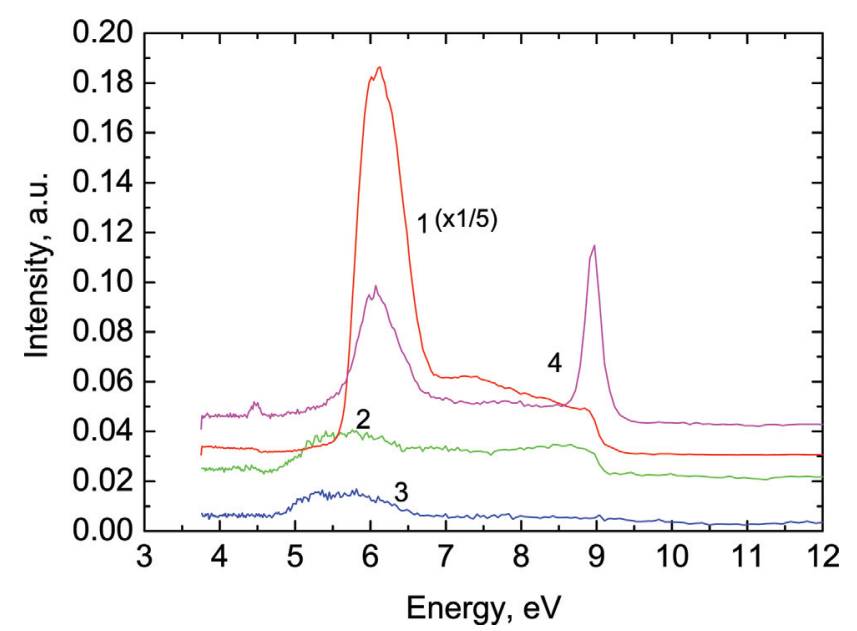

FIG. 4. (Color online) Excitation spectra monitored at $420 \mathrm{~nm}$ in $\mathrm{Al}_{2} \mathrm{O}_{3}$ doped with 50 (1), 100 (2), 500 ppm of Ti (3) and anion-deficient $\mathrm{Al}_{2} \mathrm{O}_{3}$ (4). $\mathrm{T}=8 \mathrm{~K}$. Spectra are vertically shifted.

$\mathrm{Al}_{2} \mathrm{O}_{3}-\mathrm{Ti}$ (Ref. 18) whereas the second matches the decay time constant of $\mathrm{F}^{+}$centers emission. $5,26,31$

The excitation spectra of the blue $420 \mathrm{~nm}$ luminescence band show the most noticeable changes with concentration (Fig. 4). In the samples with a low Ti content ( $<100 \mathrm{ppm})$ the main excitation band starts at $5.5 \mathrm{eV}$, exhibits a distinctive peak at $6.1 \mathrm{eV}$ that is followed by a plateau region throughout the $7-9 \mathrm{eV}$ region (Fig. 4, curve 1). This makes the excitation spectrum of the blue emission in Ti-doped aluminum oxide look like the excitation spectrum of F-centers in anion-deficient $\mathrm{Al}_{2} \mathrm{O}_{3}$ (compare Fig. 4, curves 1 and 4). The only difference is the sharp peak at $8.96 \mathrm{eV}$. However, it should be noted that this peak is detected in lightly doped $\mathrm{Al}_{2} \mathrm{O}_{3}-\mathrm{Ti}$ samples at room temperature. This observation provides a sensible argument supporting the idea that in this case the blue emission is due to the radiative decay of F-centers.

As the titanium concentration reaches $100 \mathrm{ppm}$ the excitation spectra show substantial changes: a new band appears in the low-energy part that shifts the excitation threshold to $4.7 \mathrm{eV}$. This fact indicates that when the concentration of impurity ions of titanium is about 100 ppm the excitation mechanism becomes more complicated and the blue emission can no longer be explained by radiative transitions of F-centers alone. There is yet another excitation process that contributes to the blue emission. This is consistent with the change in position and shape of this band with the concentration of $\mathrm{Ti}$ mentioned above.

Figure 5 shows the excitation spectra of $\mathrm{Ti}^{3+}$ emission monitored at $680 \mathrm{~nm}$. In the $6.2-9.2 \mathrm{eV}$ range these excitation spectra are very similar to the excitation spectra monitored at $290 \mathrm{~nm}$, which is consistent with the results of our earlier measurements. ${ }^{18,20}$ However in the 5.0-6.2 eV range there is noticeable difference in their appearance. The excitation spectra of lightly doped samples exhibit a steplike bump peaking at $\sim 6.1 \mathrm{eV}$, while those with titanium concentration $\geq 100$ ppm show a gradual rise of intensity from 5.0 to $6.2 \mathrm{eV}$. This difference can be readily understood as being caused by coherent changes in the excitation spectra of the blue emission. Indeed, the spectral overlap between the blue emission and the $\mathrm{d}-\mathrm{d}$ absorption band of $\mathrm{Ti}^{3+}$ in $\mathrm{Al}_{2} \mathrm{O}_{3}-\mathrm{Ti}$ favors the energy transfer between the emission centers associated with these bands. Therefore the shape of the excitation spectra of $\mathrm{Ti}^{3+}$ over the 5.0-6.2 eV range should reproduce the features of the excitation spectra of the blue emission. Comparison with the spectra in Fig. 4 reveals that this is indeed the case: the correlation of such features in the excitation spectra of the $\mathrm{Ti}^{3+}$ band with the shape of the excitation spectra of the $420 \mathrm{~nm}$ band as well as their regular change with the titanium concentration is fairly obvious.

Analysis of these new experimental observations suggests that the blue emission band of Ti-doped $\mathrm{Al}_{2} \mathrm{O}_{3}$ is most likely due to two different, though complementary, emission processes. The excitation features of the $420 \mathrm{~nm}$ emission band detected in undoped and lightly doped crystals shows that this luminescence stems from the radiative recombination of F-centers. On the other hand both the emission and excitation spectra show a change when the concentration of Ti exceeds $\sim 100 \mathrm{ppm}$. Apparently at this concentration the Ti ions start to contribute to the excitation and emission process, leading to the luminescence in this spectral domain.

The most popular scenario that has been discussed over decades attributes this emission to the charge-transfer transition of $\mathrm{Ti}^{4+} \cdot 1,3,4,9-14$ The luminescence is excited when an electron from the valence band is transferred to $\mathrm{Ti}^{4+}$ with creation of $\mathrm{Ti}^{3+}$ and a hole in the valence band. The de-excitation of these states results in the luminescence, following the scheme:

$\mathrm{Ti}^{4+}+\mathrm{h} v_{\mathrm{ex}} \rightarrow \mathrm{Ti}^{3+}+\mathrm{h}^{+} \rightarrow\left(\mathrm{Ti}^{4+}\right)^{*} \rightarrow \mathrm{Ti}^{4+}+\mathrm{h} v_{\text {lum }}(420 \mathrm{~nm})$.

Let us verify whether present experimental results are consistent with this model. Given that the samples are prepared in identical conditions one can expect that the intensity of $\mathrm{Ti}^{4+}$ emission should increase with the concentration of titanium. Here, we exclude the possibility of concentration quenching since for both $\mathrm{Ti}^{4+}$ and $\mathrm{Ti}^{3+}$ emissions such an effect is only observed at concentrations that exceed the maximal doping level, i.e., $1000 \mathrm{ppm}$, in the $\mathrm{Al}_{2} \mathrm{O}_{3}-\mathrm{Ti}$

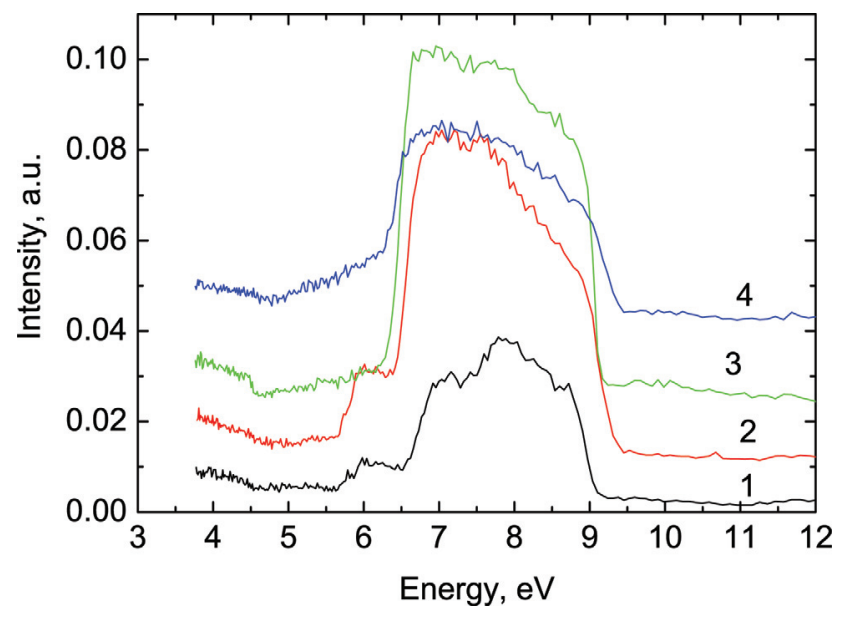

FIG. 5. (Color online) Excitation spectra monitored at $680 \mathrm{~nm}$ in $\mathrm{Al}_{2} \mathrm{O}_{3}$ doped with 10 (1), 50 (2), 100 (3), and $500 \mathrm{ppm}$ of Ti (4). T=8 K. Spectra are vertically shifted. 
samples under test (see Refs. 8 and 34, respectively). The experimental results though show that the intensity of the blue emission decreases; it totally vanishes at $1000 \mathrm{ppm}$ titanium concentration, in disagreement with the behavior expected from this model.

Another model has been put forward very recently, suggesting that the emission may be initiated by the photoionization of $\mathrm{Ti}^{3+}$ that promotes an electron to the conduction band: ${ }^{18,20}$

$$
\mathrm{Ti}^{3+}+\mathrm{h} v_{\mathrm{ex}} \rightarrow \mathrm{Ti}^{4+}+\mathrm{e}^{-}
$$

The electron can then trigger the recombination luminescence of F-center according to the scheme:

$$
\mathrm{F}^{+}+\mathrm{e}^{-} \rightarrow(\mathrm{F})^{*} \rightarrow \mathrm{F}+\mathrm{h} v_{\text {lum }}(420 \mathrm{~nm}) .
$$

where $\mathrm{F}^{*}$ stands for excited $\mathrm{F}$ center. The model implies that the recombination occurs at the defect center while the $\mathrm{Ti}^{3+}$ ion serves merely as a donor of electrons. Therefore the intensity of the emission will be controlled by the number of $\mathrm{F}^{+}$centers and the probability of the electron capture. The increase of the total amount of titanium results in the concomitant rise of the concentration of tetravalent $\mathrm{Ti}^{4+}$ ions, which creates an excess of local positive charge. Taking as reference that $2 \%$ of titanium ions reside in the tetravalent state ${ }^{2}$ one can estimate that the $\mathrm{Al}_{2} \mathrm{O}_{3}-\mathrm{Ti}$ (500 ppm) sample contains $5 \times 10^{17} \mathrm{~cm}^{-3}$ of $\mathrm{Ti}^{4+}$, while the typical concentration of oxygen vacancies in $\mathrm{Al}_{2} \mathrm{O}_{3}$ is $10^{16}-10^{17} \mathrm{~cm}^{-3} \cdot 2,25$ Therefore, at these concentrations, $\mathrm{Ti}^{4+}$ starts to compete with the oxygen vacancy in the capture of free electrons according to the following reaction:

$$
\mathrm{Ti}^{4+}+\mathrm{e}^{-} \rightarrow\left(\mathrm{Ti}^{3+}\right)^{*} \rightarrow \mathrm{Ti}^{3+}+\mathrm{h} v_{\text {lum }}(730 \mathrm{~nm}),
$$

thus reducing the numbers of carriers which are available for recombination with the $\mathrm{F}^{+}$-centers through the luminescence process (3).

This model can also account qualitatively for the small changes in the shape of the emission spectrum (broadening and redshift) as being due to the deformation of the lattice in the vicinity of the oxygen defect induced by $\mathrm{Ti}^{3+}$ when it looses an electron, in line with the discussion in Ref. 35. This, as well as the proximity of the excitation and photoionization thresholds, ${ }^{18}$ adds more confidence to the statement that the blue emission of Ti-doped aluminum oxide is due to the radiative decay of a defect F-center, stimulated by the capture of an electron, supplied by $\mathrm{Ti}^{3+}$. The involvement of the titanium ion in this emission process suggests calling the center " $\mathrm{Ti}^{4+}$-F-center."

Finally, it is worth remarking that the luminescence band at $600 \mathrm{~nm}$ manifests the type of concentration dependence which is expected for the emission of $\mathrm{Ti}^{4+}$. The intensity of this band increases with the concentration of dopant while the centroid of the excitation spectrum is positioned in the energy range of the $\mathrm{O}-\mathrm{Ti}^{4+}$ charge transfer transitions. These transitions exhibit a threshold at $4.17 \mathrm{eV}$ and are located around 5.4-6.8 eV, ${ }^{3}$ which is consistent with the luminescence excitation spectra (see Fig. 6). Such tentative assignment could reconcile the exciting experimental results

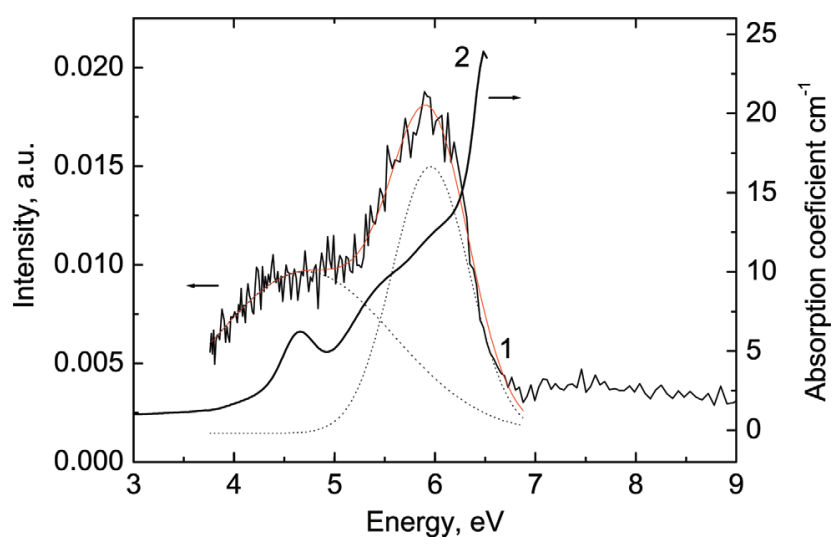

FIG. 6. (Color online) Excitation spectrum monitored at $600 \mathrm{~nm}$ in heavily doped $\mathrm{Al}_{2} \mathrm{O}_{3}$ (1000 ppm of Ti). 2-absorption spectrum of the sample. $\mathrm{T}=300 \mathrm{~K}$

and complete the model of radiative decay of high energy excitation in Ti-doped $\mathrm{Al}_{2} \mathrm{O}_{3}$.

\section{CONCLUSION}

In this work we investigated the significance of the $\mathrm{Ti}$ concentration on the luminescence of Ti-doped $\mathrm{Al}_{2} \mathrm{O}_{3}$ under excitation over a wide energy range, using synchrotron radiation. In the lightly doped $\mathrm{Al}_{2} \mathrm{O}_{3}-\mathrm{Ti}(<100 \mathrm{ppm})$ samples we detected and identified a number of previously observed emission bands, i.e., the band at $290 \mathrm{~nm}$ due to exciton localized at $\mathrm{Ti}$, the band at $325 \mathrm{~nm}$ band due to $\mathrm{F}^{+}$centers, the band at $420 \mathrm{~nm}$ due to $\mathrm{F}$ centers and the band at $730 \mathrm{~nm}$ due to emission of $\mathrm{Ti}^{3+}$. The studies of the samples with higher concentration of $\mathrm{Ti}$ allowed us to distinguish the alteration of the emission around $420 \mathrm{~nm}$ that is accompanied by related changes in the excitation spectra of this band. The appearance of the low energy band in the excitation spectra of $\mathrm{Al}_{2} \mathrm{O}_{3}-\mathrm{Ti}$ at higher concentration $(\geq 100 \mathrm{ppm}$ ) is explained as involvement of $\mathrm{Ti}^{3+}$ ions in the excitation of the $\mathrm{F}^{+}$-centers. Photoionization of $\mathrm{Ti}^{3+}$ is followed by capture of electrons at an $\mathrm{F}^{+}$-center, formation of an excited F-center and subsequent emission of a blue photon. Therefore the emission is assigned to the luminescence of $\mathrm{Ti}^{4+}-\mathrm{F}$ centers. The quenching of the emission intensity with the increase of $\mathrm{Ti}$ concentration is explained by competition between oxygen vacancies and $\mathrm{Ti}^{4+}$ centers in the capture of the electron. Finally, we put forward the hypothesis that the emission band at $600 \mathrm{~nm}$ emerging in the samples with high concentration of titanium may be due to the charge-transfer luminescence transitions of $\mathrm{Ti}^{4+}$.

\section{ACKNOWLEDGMENTS}

Partial funding for this work has been provided by Agence Nationale de la Recherche (ANR) grant SciCryo (Grant No. ANR-05-BLAN-0031), by Université Lyon 1 PPF Energie Somber-Matière Somber, and by Région Rhône-Alpes CIBLE 2008 grant DéSciR. The research leading to these results has received funding from the European Community's Seventh Framework Programme (FP7/20072013) under Grant Agreement No. 226716. 
${ }^{1}$ M. Yamaga, T. Yosida, S. Hara, M. Kodama, and B. Henderson, J. Appl. Phys. 75, 1111 (1994).

${ }^{2}$ B. D. Evans, J. Lumin. 60/61, 620 (1994).

${ }^{3}$ W. C. Wong, D. S. McClure, S. A. Basun, and M. R. Kokta, Phys. Rev. B. 51, 5682 (1995).

${ }^{4}$ W. C. Wong, D. S. McClure, S. A. Basun, and M. R. Kokta, Phys. Rev. B. 51, 5693 (1995).

${ }^{5}$ A. I. Surdo, V. A. Pustovarov, V. S. Kortov et al., Nucl. Instr. Meth. A 543, 234 (2005)

${ }^{6}$ E. Dobrovinskaya, L. Lytvynov, and V. Pischik, Sapphire and Other Corundum Crystals (Institute for Single Crystals, Kharkiv, 2002).

${ }^{7}$ S. A. Basum, T. Danger, A. A. Kaplyanskii et al., Phys. Rev. B 54, 6141 (1996).

${ }^{8}$ T. Sato, M. Shirai, K. Tanaka, Y. Kawabe, and E. Hanamura, J. Lumin. 114, 155 (2005).

${ }^{9}$ R. C. Powell, G. E. Venikouas, L. Xi, J. K. Tyminski, and M. R. Kokta, J. Chem. Phys. 84, 662 (1986).

${ }^{10}$ L. E. Bausa, I. Vergara, F. Jaque, and J. G. Sole, J. Phys. Condens. Matter 2, 9919 (1990).

${ }^{11}$ G. Blasse and J. W. M. Verweij, Mat. Chem. Phys. 26, 131 (1990).

${ }^{12}$ B. Macalik, L. E. Bausa, J. Garcia-Sole, F. Jaque et al., Appl. Phys. A 55, 144 (1992).

${ }^{13}$ G. Molnar, M. Benabdesselam, J. Borossay, D. Lapraz, P. Iacconi, V. S. Kortov, and A. I. Surdo, Radiat. Measur. 33, 663-667 (2001).

${ }^{14}$ P. S. Page, B. S. Dhabekar, B. C. Bhatt et al., J. Lumin., 130, 882 (2010).

${ }^{15}$ P. Lacovara, L. Esterowitz, and M. Kokta, IEEE J. Quant. Electr. 21, 1614 (1985).

${ }^{16}$ W. Chen, H. Tang, C. Shi, J. Deng et al., Appl. Phys. Let. 67, 317 (1995).

${ }^{17}$ A. I. Surdo, V. S. Kortov, and F. F. Sharafutdinov, Radiat. Prot. Dosim., 84, 261 (1999).
${ }^{18}$ V. B. Mikhailik, H. Kraus, M. Balcerzyk, W. Czarnacki, M. Moszyñski, M. S. Mykhaylyk, and D. Wahl, Nucl. Instr. Meth. Phys. Res. A 546, 523 (2005).

${ }^{19}$ V. B. Mikhailik and H. Kraus, Phys. Stat. Sol. B 247, 1583 (2010).

${ }^{20}$ V. B. Mikhailik, H. Kraus, M. S. Mykhaylyk, and D. Wahl, Appl. Phys. Lett. 86, 101909 (2005).

${ }^{21}$ P. C. F. Di Stefano, N. Coron, P. de Marcillac, C. Dujardin et al., J. Low. Temp. Phys. 151, 902 (2008).

${ }^{22}$ M. Luca, N. Coron, C. Dujardin, H. Kraus et al., Nucl. Instr. Meth. Phys. Res. A, 606, 545-551 (2009).

${ }^{23}$ G. Zimmerer, Radiat. Meas., 42, 859 (2007).

${ }^{24}$ A. I. Sudro, V. S. Kortov, and V. A. Pustovarov, Rad. Measur. 33, 587 (2001).

${ }^{25}$ M. Itou, A. Fujivara, and T. Uchino, J. Phys. Chem C 113, 20942 (2009).

${ }^{26}$ A. I. Sudro, V. S. Kortov, V. A. Pustovarov et al., Nucl. Instr. Meth. A 405, 408 (1998).

${ }^{27}$ N. Kristianpoller, A. Rehavi, A. Shmilevich et al., Nucl. Instr. Meth. A 141, 343 (1998).

${ }^{28}$ J. Vallayer, C. Jardin, and D. Tréheux, Opt. Mater. 16, 329 (2001).

${ }^{29}$ M. G. Springils and J. A. Valbis, Phys. Stat. Sol. B 121, 335 (1984).

${ }^{30}$ R. Ramirez, M. Tardio, R. Gonzales et al., J. Appl. Phys. 101, 123520 (2007).

${ }^{31}$ B. D. Evans and M. Stapelbroek, Phys. Rev B. 18, 7089 (1978).

${ }^{32}$ V. V. Haratunyan, V. A. Gevorkyan, and N. E. Grigoryan, Nucl. Instr. Meth. A 308, 200 (1991).

${ }^{33}$ V. N. Makhov, A. Lushchik, Ch. B. Lushchik et al., Nucl. Instr. Meth. A 266, 2949 (2008).

${ }^{34}$ J. Liu, P. Deng, and F. Gan, Opt. Mat., 4, 781 (1995).

${ }^{35}$ Yu. V. Malyukin, A. N. Lebedenko, N. L. Pogrebnyak et al., Opt. Commun. 186, 121 (2000). 